\title{
Aetiological Profile of Facial Nerve Palsy Seen in Nigerian Tertiary Hospital
}

\author{
Gabriel Toye Olajide ${ }^{1}$, Waheed Atilade Adegbiji ${ }^{2}$, Akinwale Olaleye Akinbade ${ }^{3}$ Anthony Oyebanji Olajuyin ${ }^{2}$, \\ Paul Olowoyo ${ }^{4}$
}

${ }^{1}$ ENT Department, Federal Teaching Hospital Ido-Ekiti, Nigeria/Afe Babalola University College of Medicine and Health Sciences, Ado-Ekiti/Nigeria; olajidetg@abuad.edu.ng

${ }^{2}$ ENT Department, Ekiti State University Teaching Hospital, Ado Ekiti ,Nigeria;awagbiji@yahoo.com; oyebanjiolajuyin@yahoo.com

${ }^{3}$ Department of Dental and Maxillofacial surgery, Federal Teaching Hospital Ido-Ekiti, Nigeria/Afe Babalola University College of Medicine and Health Sciences, Ado-Ekiti/Nigeria; akinwaleolaleye@gmail.com

${ }^{4}$ Department of Medicine, Federal Teaching Hospital Ido-Ekiti, Nigeria/Afe-Babalola University College of Medicine and Health Sciences, Ado-Ekiti/Nigeria; paulolowoyo@gmail.com

Corresponding Author: Dr Olajide Toye Olajide; MBBS, FWACS, FMCORL; olajidetg@abuad.edu.ng

Received 18 April 2020;

Accepted 26 May 2020;

Published 13 June 2020

\begin{abstract}
Background/Aim: Facial nerve palsy may cause facial asymmetry, functional and cosmetic impairment, and therefore imposes great psychological and social problems on the individual with the condition. The aim of this paper was to highlight the aetiological profile of facial nerve palsy (FNP) in two tertiary institutions in Ekiti, southwest, Nigeria. Methods: This was a retrospective review of patients with facial nerve palsy seen and treated at Ear, Nose \& Throat (ENT) clinic. All folders and registers of patients diagnosed with facial nerve palsy from January 2010 to December 2019 in the central, ENT and Dental medical records departments were retrieved and reviewed. The information extracted included the socio-demographic characteristics of the patients, clinical presentation, type and aetiology of FNP, side affected, diagnosis/impression, nature of impairment, type of lesion, onset of the disease, treatment and outcome. Results: Of 76 patients analysed, $48(63.2 \%)$ were males and $28(36.8 \%)$ were females given a male to female ratio of 1:1.7. Their age ranged between 5 to 72 years with a mean of $39.83 \pm 17.58 \mathrm{SD}$. The age range $21-40$ years was most commonly affected, representing $31(40.8 \%)$. The commonest cause of facial nerve paralysis was Bell's palsy in $32(42.1 \%)$, followed by trauma $28(36.9 \%)$. Of the $28(36.9 \%)$ that was caused by trauma, road traffic injury constituted $15(53.6 \%)$. Half $(50.0 \%)$ of the lesion affected right side of the face. Seventy $(92.1 \%)$ was treated medically. Majority $(37.0 \%)$ presented within one week of their symptoms. All the patients presented with deviation of mouth, followed by inability to close eye in 70 (92.1\%). Higher proportion (88.2\%) of our patients had lower motor neuron lesion. Conclusion: This study found that majority of our patients was young adults. Bell's palsy was a major cause of facial nerve paralysis followed by trauma. Most of our patient presented early and did well on conservative treatment. High index of suspicion is essential especially when patients present with injuries involving head and neck region.
\end{abstract}

Keywords: Aetiology, Profile, facial nerve palsy, tertiary hospital

\section{Introduction}

Facial nerve palsy (FNP) is a neurological condition that results from a lesion of the 7th cranial nerve leading to an acute onset of weakness or total paralysis of one or both sides of the face ${ }^{[1]}$. It is a common clinical condition that usually presents to the Otolaryngologist and Maxillofacial Surgeon. The facial nerve runs a long course from the intracranial origin to its areas of supply. It can therefore become compromised at any point along its course by various adverse conditions with resultant deficit in its functions ${ }^{[2]}$. The incidence of facial nerve paralysis is about 20-30 cases per 100,000 people $^{[3]}$. Facial nerve palsy is common in the age range of 20 - 50 years. It was said to have equal sex distribution ${ }^{[4]}$. Facial nerve palsy may induce facial asymmetry, functional and cosmetic impairment, and therefore can severely affect a patient's quality of life and imposes great psychological and social problems on the individual with the condition ${ }^{[5-9]}$. The causes of facial nerve palsy are variable and includes idiopathic Bell's palsy, trauma (nonsurgical and surgical), infections (such as herpes zoster, otitis media, leprosy, HIV, tuberculosis, meningitis), stroke and neoplasm ${ }^{[10-15]}$. It is often unilateral but can be bilateral, usually in about $40-75 \%$ cases it was unilateral palsy ${ }^{[16]}$. The aim of this paper was to highlight the aetiological profile of FNP in two tertiary institutions in Ekiti, southwest, Nigeria. 


\section{Methodology}

\section{Study Design:}

This study was a retrospective review of patients seen and treated in ENT and Dental Clinics of two tertiary Hospitals in Ekiti state.

\section{Study Setting:}

This study was conducted at Federal Teaching Hospital Ido Ekiti and Ekiti state University Teaching Hospital, Ado Ekiti. Both tertiary institutions are located within Ekiti State, south west, Nigeria. Though they both render primary and secondary health care service, they also served as a referral center for people of Ekiti state including their neighbouring states of Ondo, Kogi, Osun and Kwara.

\section{Study Protocol:}

All folders and registers of patients diagnosed with facial nerve palsy over 10 years (from January 2010 to December 2019) in the central, ENT and Dental medical records departments were retrieved and reviewed. All cases of facial nerve palsy (FNP) within this period were diagnosed and managed by resident doctors and consultants in ENT and Dental departments. Our patients also had physiotherapy treatment.

\section{Data Collection Procedure:}

Ethical Review Committee of our institution gave approval for the study. Official permission was obtained from the head of department of medical record and information unit to enable the researchers have access to registers and folders of patients with FNP that wereg seen and managed at the hospital over ten years (between January, 2010 and December 2019) period. We used research proforma to extract from the registers and folders information on socio-demographic characteristics of the patients, clinical presentation, type and aetiology of FNP, side affected, diagnosis/impression, type of lesion, duration of onset of the problem, treatment and outcome. Their radiological investigations (plain x- rays of the skull, paranasal sinuses and mastoid including Computerized Tomograph (CT) scan and MRI findings were also documented. Only few of our patients had CT scan and MRI done as the facility are not readily available in our center. HouseBrackmann scale (HBS) in assessing the degree of facial nerve injury was also documented. All patients with incomplete data and those with FNP from cerebro vascular diseases were excluded from the study.

\section{Data Analysis:}

Descriptive statistics of mean, standard deviation, percentages, frequency tables and charts were used to summarize the data. This data summary was performed utilizing Statistical Package for Social Sciences (SPSS), (Windows Version 19.0, Chicago, IL, U.S.A.).

\section{Results}

Of 76 patients analysed, 48(63.2\%) were males and 28(36.8\%) were females giving a male to female ratio of $1: 1.7$. Their ages ranged from 5 to 72 years with a mean of $39.83 \pm 17.58 \mathrm{SD}$. The age range 21-40 years was most commonly affected representing $31(40.8 \%)$ More than half $(56.6 \%)$ were married. Majority (44.7 $\%)$ had tertiary education. Large percentages (39.5\%) are civil servants. Table 1.
Table 1: Showing demographic characteristics of patients

\begin{tabular}{|c|c|c|}
\hline Variable & Frequency & Percentage \\
\hline Age Range (Years) & & \\
\hline $0-20$ & 10 & 13.2 \\
\hline $21-40$ & 31 & 40.8 \\
\hline $41-60$ & 23 & 30.3 \\
\hline $61-80$ & 12 & 15.8 \\
\hline \multicolumn{3}{|l|}{ Gender } \\
\hline Male & 48 & 63.2 \\
\hline Female & 28 & 36.8 \\
\hline \multicolumn{3}{|l|}{ Marital Status } \\
\hline Single & 31 & 40.8 \\
\hline Married & 43 & 50.6 \\
\hline Widow & 2 & 2.6 \\
\hline \multicolumn{3}{|l|}{ Educational Level } \\
\hline Nil & 4 & 5.3 \\
\hline Primary & 10 & 13.2 \\
\hline Secondary & 28 & 36.8 \\
\hline Tertiary & 34 & 44.7 \\
\hline \multicolumn{3}{|l|}{ Occupational status } \\
\hline Unemployed & 19 & 25.0 \\
\hline Farming & 5 & 6.6 \\
\hline Business & 19 & 9.2 \\
\hline Civil servant & 30 & 39.5 \\
\hline Artisan & 3 & 3.9 \\
\hline \multicolumn{3}{|l|}{ Type of Lesion } \\
\hline \multicolumn{3}{|l|}{ Lower Motor Neuron } \\
\hline Upper Motor Neuron & 67 & 88.2 \\
\hline & 9 & 11.8 \\
\hline Outcome of treatment & & \\
\hline Full recovery & 49 & 64.5 \\
\hline Partial recovery & 15 & 19.7 \\
\hline No recovery & 5 & 9.2 \\
\hline Loss to follow up & 5 & 6.6 \\
\hline
\end{tabular}

The commonest cause of facial nerve palsy is Bell's palsy in $32(42.1 \%)$, followed by trauma $28(36.9 \%)$, Herpes zoster $9(11.8 \%)$, Otitis media $4(5.4 \%)$, Otitis externa malignant $2(2.6 \%)$ and Tumour 1(1.3\%). Of the $28(36.9 \%)$ that were caused by trauma, road traffic injury constituted $15(53.6 \%)$, assault 6(21.4\%), gunshot 4 (14.3\%), fall from height $2(7.1 \%)$ while iatrogenic due to surgical procedure was recorded in only one $(3.6 \%)$ patient. Table 2.

Table 2: Showing aetiology / causes of facial nerve

\begin{tabular}{|l|l|l|}
\hline Causes & Frequency & Percentage \\
\hline Bell's palsy & 32 & 42.1 \\
Otitis media & 4 & 5.3 \\
Herpes Zoster & 9 & 11.8 \\
Trauma & 28 & 36.9 \\
Assault 6 & & \\
Gunshot 4 & & \\
Fall from height 2 & & \\
Road Traffic Injury 15 & & \\
Iatrogenic 1 & 2 & 2.6 \\
Otitis External & 1 & 1.3 \\
Tumor & $\mathbf{7 6}$ & $\mathbf{1 0 0 . 0}$ \\
\hline Total & \multicolumn{2}{|l}{} \\
\hline
\end{tabular}


Majority (37.0\%) presented within one week of their symptoms, followed by $32.9 \%$ of patients that came after 4 weeks of their symptoms. Figure 1.

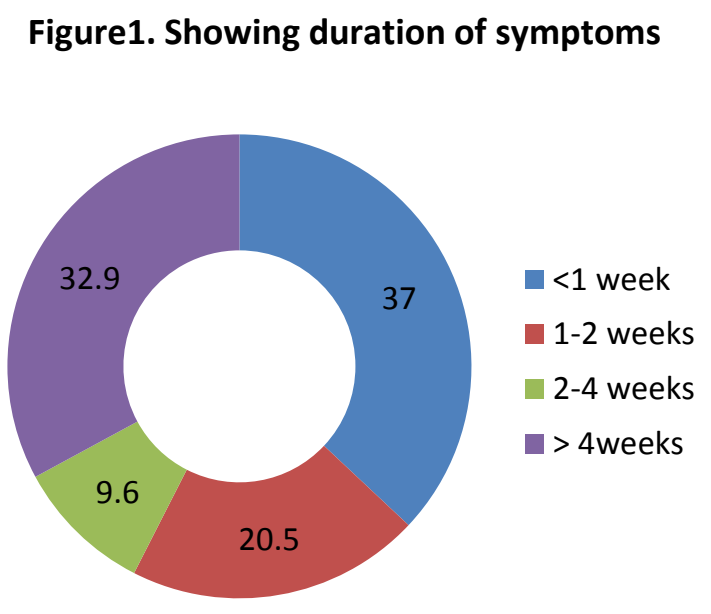

Based on House-Brackmann scale of classifying facial nerve injury clinically ${ }^{17}, 55(72.4 \%$ ) of our patients had grade II ( mild dysfunction), 13(17.1\%) had grade III (moderate dysfunction), while $8(10.5 \%)$ had grade V (severe dysfunction). Half (50.0\%) of the lesion affected Right side of the face. Figure 2.

\section{Figure 2. Showing laterality of the lesion}

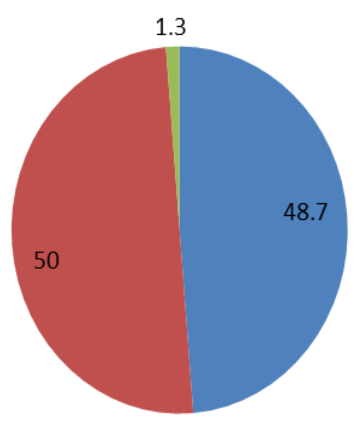

night

- Left

both

Almost all the patients presented with deviation of mouth, followed by inability of closing their eyes in $70(92.1 \%)$. Table 3 .

Table 3: Showing clinical presentation /features

\begin{tabular}{|l|c|c|}
\hline $\begin{array}{l}\text { Clinical Presentation/ } \\
\text { Features }\end{array}$ & $\begin{array}{c}\text { Frequency } \\
(\mathbf{N})\end{array}$ & $\begin{array}{c}\text { Percentage } \\
(\mathbf{\%})\end{array}$ \\
\hline Deviated mouth & 74 & 97.4 \\
\hline Inability to close eye & 70 & 92.1 \\
\hline Otalgia & 66 & 86.8 \\
\hline Otorrhoea & 13 & 17.1 \\
\hline Tinnitus & 20 & 26.3 \\
\hline Rashes at the ear & 9 & 11.8 \\
\hline Speech problem & 14 & 18.4 \\
\hline Tearing & 45 & 59.2 \\
\hline Foreign body sensation & 40 & 52.6 \\
\hline
\end{tabular}

$N B$ : Some patients have more than on clinical features

Higher proportion $(88.2 \%)$ of our patients had lower motor neuron lesion. Seventy $(92.1 \%)$ was treated medically, $4(5.3 \%)$ had surgical intervention while $2(2.6 \%)$ were referred to other centre. Figure 3.
Figure 3: Showing treament modality

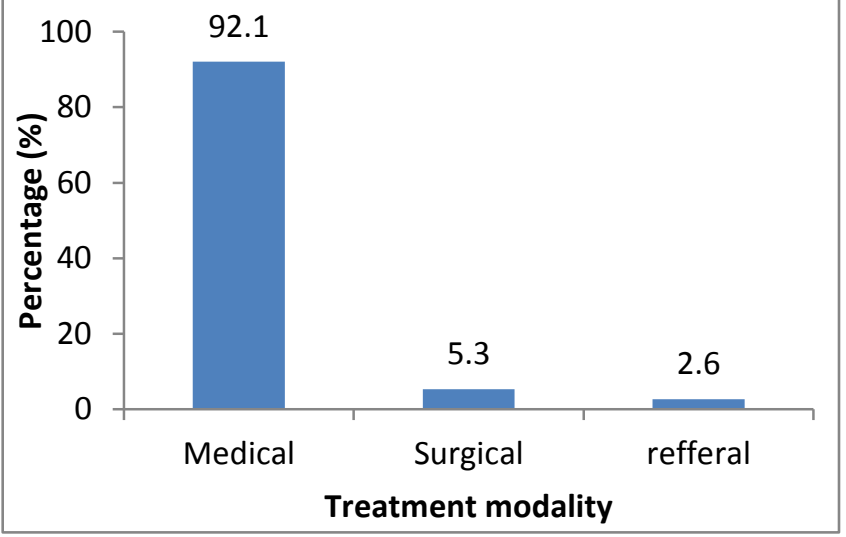

\section{Discussion}

Facial paralysis is one of the common problems leading to facial deformity. Our study had shown that facial palsy cut across all age groups; however the age group of 21 - 40 years was mostly affected in this study which constitutes young adults. Other studies also recorded similar trends ${ }^{[7,18-22]}$. Male preponderance was also recorded in our study. This was similar to other studies ${ }^{[7,18,20-, 23]}$. The young adults and male preponderance in our study might have been due to their higher vulnerability to environmental hazards especially in the course of daily activities which sometimes are more strenuous in males than their female's counterparts. Major cause of FNP in our study was Bell's palsy which was a lower motor neuron palsy of acute onset and idiopathic in origin. Bell's palsy was recorded as being the commonest cause of facial palsy by other researchers ${ }^{[7,18-21]}$. It represents about $42.1 \%$ in our report. It was thought to account for approximately $60-75 \%$ cases of acute unilateral facial paralysis generally ${ }^{[24]}$. Trauma was second commonest cause of facial nerve palsy in this study (36.9\%), and majority are due to road traffic injuries. Afolabi et al made similar observation in their study where trauma was the predominant cause of FNP in the younger age group ${ }^{[18]}$. Simple radiological investigations were done to exclude other causes of facial palsy. Majority of our patients presents within one week of the onset of their symptoms. This might be attributed to the cause of FNP. Traumatic cases may be picked along with other pathology in the body as they present in the hospital. Also for the infective causes the associated otalgia and occasionally tinnitus made their presentation very early as those symptoms may be unbearable to them. Also, this study showed that our patients were predominantly civil servants and larger percentages were educated hence they tend to seek medical attention early. Early presentation, diagnosis and treatment usually improve prognosis. Unilateral involvement was more common than bilateral in our record, this is in tandem with others studies ${ }^{[7,19,20]}$. Right side was mostly affected in about half of our studied patients. Only $1.3 \%$ had bilateral involvement. It is important to note that bilateral facial nerve palsy is a rare condition. However, Ogunmade et al ${ }^{[25]}$ and Owolabi et al ${ }^{[26]}$ reported bilateral FNP in a homozygous haemoglobin $\mathrm{S}$ and in a Nigerian patient with Bell's palsy respectively. In our study, lower motor neuron lesion was found to be more common than the upper motor neuron lesion. This agrees with report from other studies $[7,22,27]$. Management of FNP is multidisciplinary as aetiology may be diverse. Majority of our patients were managed medically with analgesics, anti-inflammatory, antiviral, and antibiotics apart from being treated for any/ associated underlying problem. Large percentage of our patient had supportive treatment from 
physiotherapy department. About $64.5 \%$ of our patients had full recovery. Few had poor recovery and some were lost despite long time follow up. Large percentage of our patients presented with mild facial dysfunction (grade II) based on House-Brackmann scale (HBS) and early presentation in the hospital after the onset of their problem along with early intervention might have been responsible for full recovery in majority of them.

Limitation of this study includes inability to conduct electrophysiological test for our patients that may need it as it is not readily available. Few cases were lost for a long time to follow up due to the nature of our socio-cultural belief which makes patient sometimes defaulted once there is slight improvement in their health condition.

\section{Conclusion}

This study found that majority of our patients were young adults, Bell's palsy was a major cause of facial nerve paralysis followed by trauma. Most of our patient presented early and did well on conservative treatment. High index of suspicion is essential especially when patients presents with injuries involving head and neck region.

\section{Funding}

There was no financial support.

\section{Competing interests}

All the authors declare no competing interests.

\section{References}

[1] Parnes L. (2004): Newly diagnosed with Bell's palsy. Power point slides from a lecture presented to second year medical school students at the University of Western Ontario

[2] Holland NJ, Weiner GM. Recent developments in Bell's palsy. BMJ. 2004;329:553-557.

[3] Junior NA, Junior JJJ, Gignon VF, Kitice AT, Prado LSA, Saritos VGW, et al. Facialnerve palsy: Incidence of differen Ethiologies in a Tertiary Ambulatory. Int Arch Otorhinolaryngol. 2009;13(2):167- 171.

[4] Hasan G, Hasan A, Kaur K, Ahmad M, Shafi M. The facial nerve: The anatomical and surgical important. J K Practitioner. 2005;12(1):53-7.

[5] Stew B, Williams H. Modern management of facial palsy: A review of current literature. Br J Gen Pract. 2013;63(607): 109-110.

[6] Uju IM, Ugonna AE. Otorhinolaryngological Disorders Implicated in Facial Nerve Paralysis in a Tertiary Hospital in Port Harcourt. Asian Journal of Medicine and Health 17(2): 1-8, 2019;

[7] Adegbiji WA, Aremu SK, Olatoke F, Olajuyin AO. CLINICO-EPIDEMIOLOGICAL PATTERN OF FACIAL NERVE PALSY IN EKITI,2018;7 (1): 38 -41.

[8] Kaylie DM, Wax MK,Weissman JL. Preoperative facial muscle imaging predicts final facial function after facial nerve grafting. American Journal of Neuroradiology. 2003; 24 :326-30.

[9] Chang Il Cha, Chang Kee Hong, Moon Suh Park, and Seung Geun Yeo. Comparison of Facial Nerve Paralysis in Adults and Children. Yonsei Med J 49(5):725 - 734, 2008.

[10] Mavrikakis I. Facial Nerve Palsy: anatomy, etiology, evaluation, and management. Orbit 2008; 27:466-474.

[11] Lee V, Currie Z, Collin JRO. Ophthalmic management of facial nerve palsy. Eye 2004; 18: 1225-1234.

[12] MacIntosh PW, Aaron MF. Update on the ophthalmic management of facial paralysis. Surv Ophthalmol 2019; 64: 79-89.

[13] Rowland S, Hooper R,Hughes R, Burney P. The epidemiology and treatment of the Bell's palsy in UK. Eur J Neurol 2002;9:63-7.

[14] Evans AK, Licameli G, Brietzke S, Whiitermore K, Kenna M. Pediatric facial nerveparalysis. Patients, management and outcomes. Int $\mathbf{J}$ Pediatr Otorhinolaryngol 2005;69:1521-8.

[15] Kim IS, Shin SH, Kim J, Lee WS, Lee HK. Correlation between MRI and operative findings Bell's palsy and Ramsay Hunt syndrome. Yonsei Med J 2007;48: 963-8.

[16] Ciorba A, Corazzi V, Conz V, Bianchini C, Aimoni C. Facial nerve paralysis in children. World J Clin Cases. 2015;3(12):973-79.

[17] House JW, Brackmann DE. Facial nerve grading system. Otolaryngol Head Neck Surg. 1985 Apr. 93(2):146-7.

[18] Afolabi OA, Alabi BS, Lasisi OA. Aetiological Profile of Facial Nerve palsy in North Central, Nigeria. East and Central African Journal of Surgery. 2008;13(1):101-103

[19] Jain G, Verma V. Right sided facial palsy more common in males while left sided facial palsy more common in females. Int. J Res Med Sci. 2018;6(7):2291-2294.

[20] Lamina S, Hanif S. Pattern of facial palsy in a typical Nigerian specialist hospital African Health Sciences 2012; $\quad$ (4): $\quad 514 \quad-517$ http://dx.doi.org/10.4314/ahs.v12i4.18.

[21] Maduagwu S, Umeonwuka C I, Saidu Z, Oyeyemi AY, Dabkana T, Jaiyeola OA. Review of Facial Nerve Palsy at a Tertiary Hospital in Maiduguri, Nigeria. American Journal of Health Research 2016; 4(4): 100-103.

[22] Gbiri CA, Sumaila FG, Usman JS. PREVALENCE AND AETIOLOGICAL PROFILES OF FACIAL NERVE PARALYSIS: A FIVE-YEAR REVIEW OF TERTIARY HEALTH INSTITUTIONS IN KANO STATE, NORTHWESTERN NIGERIA. Journal of Community and Health sciences. 8(1) 32-40.

[23] Osaguona VB. Facial nerve palsy: the need for an ophthalmologist in its management. Annals of Medical and surgical practice. 2019;4(2):140-144.

[24] Newadkar UR, Chaudhari L, Khalekar Yogita K. Facial Palsy, a Disorder Belonging to Inluential Neurological Dynasty: Review of Literature. North Am J Med Sci 2016;8:263-7

[25] Ogundunmade BG and Jasper US. Homozygous hemoglobin $\mathrm{S}$ (HbSS) presentingwith bilateral facial nerve palsy: a case report. BMC Research Notes 2014, 7:729. http://www.biomedcentral.com/1756-0500/7/729

[26] Owolabi LF, Zayyad F. Simultaneous Bilateral Bell's palsy in a Nigerian man. Journal of Medicine in the Tropics (2013) 15:2: 165 - 167

[27] Kah AT, Hanom F, Annur. (2011): A systematic approach to facial nerve paralysis. Webmed Central Ophthalmology. 2 (4):1856. 